acenados ou simplesmente ignorados (14). Mas nossa intenção foi a de examinar apenas algumas das características que mais difereciam o processo civil do tipo sociallista daquele disciplinado nos países da Europa Ocidental, indicando de tal maneira as mais importantes linhas de divergência que, nos últimos decênios, se manifestaram no ambito das divergência que, nos últimos decênios, se manifestaram no âmbito das legislações processuais dos "civil law contries", admitido que (como entendemos), no grupo dos sistemas assim denominados do "civil law" devam continuar a considerar-se partícipes também os Países da Europa Oriental.

$\frac{14 . \mathrm{N} . \mathrm{T}}{1 .}-\mathrm{O}$ contrcle jurisdicional da constitucionalidade das leis, ou garantia constitucional como o mandado de segurança, inexistem no sistema juridico soviético: des e amplitude consagrados na legislaçáo outros nâo socialistas, pelo menos nos molclaração de inconstitucionalidade" dá a nosso supr. "A chamada "açáo direta de deamplos aio que os exercidos pela Corte Suprema dos Estados Unidos. Os paises runal especial Tribunal contitunte, em sua maioria, pelo controle através de TriConstituzionale" da Italia) Dos paise socialistas apa pedo con 1963, criou uma Corte Constitucional. A respeito do assunto, ver José Luiz de Anhą

Mello, in "Da Separaçáo de Poderes à Guarda da Constitulą̧ão".

\section{RESPONSABILIDADE PENAL}

\section{Prớ. Antônio José Fabrício Leiria}

1. No plano das relações, que norteia todo o ordenamento jurídico, a responsabilidade penal aparece relacionada com a imputabilidade, assim como a pena se relaciona com o delito. Responsabilidade e pena, portanto, são conseqüências de causas eficientes, tendo aquela como pressuposto a imputabilidade e esta o delito.

Temas, como este aqui equacionado, polarizam o pensamento de filósofos e juristas, que os têm examinado sob os mais complexos e variados aspectos. Longe de qualquer pretensão inovatória, procuraremos focalizar a problemática da responsabilidade penal dentro de uma visualização estritamente valorativa, em sintonia com a índole e a tendência do moderno Direito Penal.

2. Embora vivendo dentro de um ordenamento realizado, natural e necessário, formado pelo espetáculo da $\mathrm{Na-}$ tureza, o homem toma consciência do seu poder criador. E, assim conscientizado pelo despertar da razão, busca ele, dentro desse ordenamento natural e necessário a que está integrado, descobrir uma nova ordem possível e realizável. Por tal forma, lançam-se as bases de formação e estrutura da ordem jurídica que, criada pelo homem, está sedimentada no mundo dos valores e objetiva ordenar um convívio capaz de conduzir a criatura humana pelas linhas que a levam aos fins que permitem a sua realização de ser contingente.

3. Neste preciso instante em que, pela racionalidade, o homem descobre seu poder criador e ordenador, numa tomada de consciência de si mesmo, simultâneamente, é vislumbrada a sua responsabilidade frente à vida e ao mundo. Equaciona-se o problema aqui enfocado que é visualizado no tempo sob as mais diferentes formas. Pensadores dos mais variados ramos do conhecimento e seguidores das mais diversas doutrinas filosóficas procuram, de acordo com suas 
convicções, situar a responsabilidade do homem no turbilhão da vida.

4. No âmbito do Direito Penal, sob a influência do direito bárbaro, oriundo das tribos germânicas, a responsabilidade aparece com uma roupagem puramente objetiva, constituída pelo simples nexo de casualidade material que vincula o fato ao seu ator. Abstraído e ofuscado é o aspecto subjetivo da matéria. Esta faceta da responsabilidade, onde se situa todo o conteúdo humano do problema, é aflorada no cenário jurídico pela influência do Direito Romano que, conjugado com o Direito da Igreja, realça o sentido humano do assunto, enriquecendo-o de subjetividade e fazendo com que a responsabilidade, em todas as legislações, viesse a se tornar o centro gravitacional das mais profundas pesquisas e meditações filosófico-jurídicas, especialmente no campo do direito punitivo.

5. Impregnada de imensa carga de subjetividade valor, a responsabilidade penal gerou doutrinas e formou Escolas. Entre estas, pontificando no tempo, salintam-se a Escola Clássica e a Escola Positiva; a primeira, alicerçada no Direito Natural e ordenada pela figura ímpar de Francisco Carrara, com base no livre arbítrio, situa a responsabilidade penal na liberdade moral do homem - "O HOMEM É RESPONSÁVEL POR SER MORALMENTE LIVRE”; a segunda, com Henrique Ferri e Raphael Garofalo, sob a influência da filosofia positivista de Augusto Comte, voltada para o dado da experiência empírica e para o determinismo, coloca a responsabilidade penal na sociabilidade do homem: - "O HOMEM É RESPONSÁVEL POR SER SOCIAAL". Em tais condições, dađa a riqueza e a fertilidade axiológica do tema, clássicos e positivistas, num embate de autênticos gladiadores do pensamento, fazem vibrar o sistema nervoso de todas as legislações penais.

6. Como se percebe pelas coordenadas gerais singelamente alinhadas, o problema enfocado, para o seu pleno descortinamento jurídico, requer pesquisas de cunho ontológico e axiológico. Assim, estando a responsabilidade penal intimamente relacionada com a ordem jurídica, como primeira tomada de posição, cumpre situar o Direito que, segundo mostra o eminente Professor Armando Câmara radica na natureza racional e social do homem e é descoberto pela razão. Por tal maneira, a ordem jurídica evi- dencia-se como exclusiva da sociedade humana, porque somente nesta impera o mundo da racionalidade. Pela razão o homem descobre os valores, acordes com os fins da natureza humana. $\mathrm{E}$ sob as inspirações do valor de Justiça ele ordena a convivência social, de modo a possibilitar a sua marcha incessante na busca da plenitude de ser.

7. Estas normas e convívio reguadoras das relações interpessoais conduzem o homem, através da liberdade, por linhas possíveis de realização do bem comum, como expressão e concretização do valor Justiça, visto que no bem comum se sintetiza o fim social do homem. Deste modo, a ordem jurídica retrata uma posição do ser contingente do homem quando persegue certas e determinadas metas. São os fins descobertos pela razão e realizados pela liberdade. Mas, sendo livres os atos humanos, não raro, o homem se transvia nesse caminho, nega aqueles fins e volta-se para 0 mundo dos desvalores, ingressando na faixa da ilicitude que the frustra a realização de seu ser social. Por isso em todo o ato ilícito há sempre um valor ferido, em grau maior ou menor. Negando livremente o valor e realizando os fins contrários ao convívio, quando outros lhe eram apontados pela razão, e se abriam à possibilidade de realização, nas circunstâncias sociais que o cercavam, é o homem culpável; e "se reprochara al autor el que no ha actuado cf. al Derecho, el que se ha decidido..." R. Maurach - Ed. espanhola, vol. I - pág. 14 in fine.

Pela racionalidade, o homem se conscientiza da existência do mundo dos valores e, pela liberdade, realiza opção entre o valor e o desvalor, afirmando ou negando o bem comum A opcão pelo desvalor configura o ato ilícito que gera a culpa, trazendo como conseqüencia a responsabilidade que em última análise, encontra sua fonte geradora na razão e realizadora na liberdade que comanda o poder de opção zão e realiza

8. Neste particular, reside um dos equívocos da concepção positivista de Ferri e de Garofalo, quando situam a responsabilidade penal na sociabilidade do homem. Pois, a responsabilú é algo a que o homem se vincula como intesociabilidade é algo a que condições análogas a outras espécies gragárias pertencentes a este gênero. Com efeito, não é a sociabilidade, em si mesma, que caracteriza o homem como pessoa. A pessoalidade surge em função da ra- 
cionalidade, que é faculdade inerente e exclusiva da sociedade humana. Logo, o ordenamento jurídico se erige na base da razão. A responsabilidade social existe, em última análise, por causa da racionalidade e, mais precisamente, pela censurabilidade que é juízo de desvalor do ato transferido pela sociedade ao autor do ilícito. Daí afirmar Sebastían Soler: "que o erro da concepção positivista radica em chamar social a responsabilidade, ao invés de chamá-la jurídica" (Direito Penal Argentino - vol. II - pag. $37-1^{\mathrm{a}} \mathrm{Ed}$.). Em verdade, a responsabilidade social só aparece em função da responsabilidade jurídica, que tem como pressuposto necessário a racionalidade.

9. Configurada na razão a causa primeira de que a responsabilidade é conseqüência última, fica evidenciado que para se aferir da responsabilidade penal, como primeira tomada de posição, dever-se-á perquirir da potencialidade racional que leva até suas últimas ramificações e conseqüên cias a marca da estrutura orgânica e funcional da razão. Estrutura esta que é síntese da soma de uma série de fatores endógenos e exógenos, os quais convergindo para um mesmo ponto, concorrem para a formaç̃o da personalidade, caracterizando e individualizando o homem perante à sociedade. Neste sentido, pesquisando as motivações e o funcionamento da razão, com seus reflexos na formação da personalidade, voltam-se a Biologia, a Psicologia, a Psiquiatria, a Sociologia e diversas outras ciências que integram a Criminologia. Todas elas, como ciências da natureza, calcadas na experiência sensível, elaboram juízos de realidade, deixando num plano à margem a pesquisa sobre a validade.

10. O exame desta carga axiológica que a responsabilidade traz em seu conteúdo se realiza através do Direito Penal que, como ciência culturalista, sem desprezar o dado da realidade sensível, elabora juízos de valor. $\mathrm{E}$, assim, utilizando-se das elaborações formuladas no plano empírico pelas ciências da natureza, o Direito Penal, com sua característica normativa e teológica, desvenda o conteúdo jurídico da responsabilidade, o qual radica na capacidade que o agente possui para distinguir o valor do desvalor, isto é, um ato lícito de outro penalmente ilícito, conjugando-se esta capacidade que emana da razão, com o poder de autodeterminar-se que é fruto da liberdade. Conseqüentemente, exteriorizando-se pela capacidade de entendimento e pelo poder de autodeterminação, racionalidade e liberdade situam-se no vér- tice da pirâmide de onde surge a responsabilidade penal. $\mathbf{E}$, assim se explica a afirmativa de que sem racionalidade e sem liberdade não há responsabilidade. O indivíduo só é responsável pelos atos que pratica com consciência e liberdade.

11. Partindo da razão e da liberdade, para se chegar à responsabiliđađae, no centro da trajetória, com emanações plenamente perceptíveis, aparecem uma capacidade e um poder, que funcionam como causas imediatas da responsabilidade penal. Com efeito, neste particular, ensina o eminente Professor José Salgado Martins: "a essência da responsabilidade penal se encontra, em última análise, na capacidade de imputação do agente e no poder de auto determinar-se à vista dos motivos que lhe solicitam a vontade". (Sistema de Direito Penal Brasileiro - pag. 271).

Desta forma, dentro de um prisma valorativo, pela racionalidade que descobre valores, é aferida a capacidade de imputação e, pela liberdade que realiza a opção entre o valor e o desvalor, resolve-se o poder de autodeterminação. Assim, após constatada a normalidade destas duas condiçốes: capacidade de entendimento e poder de auto determinar-se, através de um critério valorativo e finalista, chega-se à análise dos diferentes graus da culpabilidade, que é pressuposto necessário e direto da responsabilidade penal.

12. O novo Código Penal Brasileiro, quando regula esta matéria, embora alteradno a nomenclatura do Diploma anterior, nenhuma modificação profunda traz sobre o assunto da responsabilidade penal que permanece, em nossa legislação, alicerçada nos fundamentos da Escola Clássica. Vejamos, a título de comparação, como se encontra regulada a responsabilidade penal nos Códigos de 1940 e 1969, Título III dos artigos 22 a 24 , e. 31 a 34 , respectivamente:

\section{Código PENAL DE 1940}

\section{Da Responsabilidade}

Art. 22 - isento de pena o agente que, por doença mental ou desenvolvimento mental incompleto ou retardado, era ao tempo da ação ou da omissão, inteiramente incapaz de entender o caráter criminoso do fato ou determinar-se de acordo com esse entendimento. 
Parágrafo único - A pena pode ser reduzida a dois terços, se o agente, em virtude de perturbação da saúde mental ou por desenvolvimento mental incompleto ou retar dado, não possuía, ao tempo da ação ou da omissão, a plena capacidade de entender o caráter criminoso do fato ou de determinar-se de acordo com esse entendimento.

Art. 23 - Os menores de dezoito anos são penalmente irresponsáveis, ficando sujeitos às normas estabelecidas na legislação especial.

Art. 24 - Não excluem a responsabilidade penal:

I - a emoção ou a paixão;

II - a embriaguez, voluntária ou culposa, pelo álcool ou substância de efeitos análogos.

$\S 1^{\circ}-E$ isento de pena o agente que, por embriaguez completa, proveniente de caso fortuito ou forç maior, era, ao tempo da acão ou da omissão, inteiramente incapaz de entender o caráter criminoso do fato ou de determinar-se de acordo com esse entendimento.

$\delta 2^{\circ}$ - A pena pode ser reduzida a dois terços, se o agente, por embrdiaguez, proveniente de caso fortuito ou força maior, não possuía, ao tempo da ação ou da omissão, a plena capacidade de entender o caráter criminoso do fato ou determinar-se de acordo com esse entendimento.

\section{Código PENAL DE 1969}

\section{Da Imputabilidade Penal}

Art. 31 -Não é imputável quem, no momento da omissão, não possuía a capacidade de entender o caráter ilícito do fato ou determinar-se de acordo com esse entendimento, em virtude de doença mental ou desenvolvimento mental incompleto ou retardado.

Parágrafo único - Se a doença ou a deficiência mental não suprime, mas diminui consideravelmente a capacidade de entendimento da ilicitude do fato ou a de autodeterminação, não fica excluída a imputabilidade, mas a pena pode ser atenuada, sem prejuízo do disposto no artigo 94 .

Art. 32 - Não é igualmente imputável o agente que, por embriaguez completa proveniente de caso fortuito ou força maior, era, ao tempo da ação ou da omissão, inteiramente incapaz de entender o caráter criminoso do fato ou de determinar-se de acordo com esse entendimento.
Parágrafo único - A pena pode ser reduzida de um a dois terços, se o agente, por embriaguez proveniente de caso fortuito ou força maior, não possuía, ao tempo da ação ou da omissão, a plena capacidade de entender o caráter criminoso do fato ou de determinar-se de acordo com esse entendimento.

Art. 33 - O menor de dezoito anos é inimputável, salvo se, já tendo completado dezesseis anos, revela suficiente desenvolvimento psíquico para entender o caráter ilícito do fato e determinar-se de acordo com esse entendimento. Neste caso, a pena aplicável é diminuída de um terço até a metade.

Art. 34 - Os meonres de dezesseis anos, bem como os menores de dezoito e maiores de dezesseis inimputáveis, ficam sujeitos às medidas educativas, curativas ou disciplinares determinadas em legislação especial.

13. Pela comparação feita, verifica-se que, em tema de responsabilidade, o Código Penal de 1969 seguiu as mesmas diretrizes fundamentais do Código de 1940, nenhuma alteração substancial fazendo ao que já se encontrava regulado no diploma anterior, exceto na parte em que se estabelece os limites da meonridade, aos efeitos da responsabilidade penal (C.P.1940 - art. 23 - C.P.69 - arts. 33 e 34). Nas duas legislaçōes permanece evidenciado o caráter ético da matéria. Entre os três sistemas tradicionais que a procuram fixar em seus pressupostos, com base na culpa moral (sistema biológico - sistema psicológico e sistema bio-psicológico), seguiu o legislador brasileiro, em ambos os diplomas legais, como se infere das transcrições referidas, o critério aconselhado pelo sistema bio-psicológico ou misto. Dentro deste sistema, que é uma reunião dos métodos biológico e psicológico, a responsabilidade penal do homem adulto fica excluída, quando o agente, no momento da ação ou da omissão, por doença mental ou desenvolvimento mental incompleto ou retardado, é incapaz de entender o caráter criminoso do fato ou de determinar-se de acordo com esse entendimento. Por outro lado, se a doença mental não anula de todo a capacidade de entendimento e o poder de autodeterminação, a responsabilidade não ficará excluída, mas diminuída, facultando-se ao juiz uma atenuação na pena.

14. Consoante à orientação seguida por nosso legislador, não ficam incólumes e livres das malhas da lei aqueles tipos anômalos que possuem intervalos de plena lucidez, 
como os epiléticos, por exemplo, quando, nesses intervalos de plenitude das faculdades mentais, venham a cometer um delito, eis que há uma exigência legal no sentido de ser a perturbação psíquica concomitante ao momento da ação ou da omissão criminosa. Não basta, pois, a averiguação puramente biológica do estado de doença mental ou desenvolvimento mental incompleto ou retardado, bem como a mera verificacão do desajuste momentâneo, para que o agente seja eximido de responsabilidade. necessário que a doença mental ou o desenvolvimento mental incompleto ou retardado, no momento da ação ou da omissão, sejam constatados como atuantes em seus efeitos patológicos, de molde a causar no agente uma certa e determinada perturbação da inteligência e da vontade, afetando-lhe o entender e o querer, para fazer com que o autor do fato se desvie pelo mundo dos desvalores.

Assim, frente ao sistema seguido pelos Códigos de 1940 e 1969, não fica o aplicador da lei jungido à constatação pura e simples de um laudo médico que atesta um determinado estado de morbidez do delinqüente. A índole jurídica do Direito Penal, através dos códigos referenciados abre uma nova porta ao juiz para permitir que este não se limite ao exame puramente biológico, mas realize, também, uma análise valorativa da ação ou da omissão, no momento consumatório do fato criminoso, para concluir sobre o grau da culpa e, conseqüentemente, da existência da responsabilidade penal que tem na culpabilidade seu pressuposto necessário e que, em última "ratio", vem a ser a capacidade de imputação do agetne.

15. Com efeito, a imputabilidade pode ser conceituada como o conjunto de condições pessoais de um determinado indivíduo que o faz capaz de ser culpado. $\mathrm{E}$, assim ela antecede à culpabilidade, pela mesma forma que esta e precedente da responsabilidade. A imputabilidade, portanto, é um "status" condicionante da culpabilidade que, por seu utrno, é fonte imediata da responsabilidade penal, sendo que esta só existe no sujeito que decide e age conscientemente. Neste sentido, a imputabilidade pode situar-se no ámbito da teoria do delito. Relaciona-se com a estrutura ontológica do crime, pois, ainda que não se constitua em elemento estrutural do "ente jurídico" de que fala Carrara, é um pressuposto da culpabilidade que é o elemento subjetivo do delito.

Em verdade, é pela imputabilidade que o autor de de- terminado fato compromete sua capacidade de entendimento e seu poder de querer; capacidade que radica na razão e poder que se fundamenta na liberdade. Logo, na razão e na liberdade, encontram-se inseridas as causas primeiras que conduzem à imputabilidade moral, cujos postulados afirmam o caráter ético do Direito Penal. ${ }^{1}$

16. Realmetne, é pela imputabilidade que se processa a interligação das ciências criminológicas com o Direito Penal, trazendo-se para o mundo jurídico toda a problemática da Antropologia e da Sociologia Criminal, com seus inúmeros reflexos na capacidade de entendimento e no poder de opção e decisão do homem.

E aqui que os juízos de realidade, próprios das ciências positivas, se interrelacionam com os juízos de valor, característicos das ciências culturalistas, para fazerem surgir na esfera do Direito a responsabilidade penal com toda a sua plenitude. ${ }^{2}$

17. Nosso direito objetivo, como se vê do confronto entre os dois Códigos, não define a responsabilidade penal. O legislador patrício, situando-a na razão que descobre valores e na liberdade que os realiza, preferiu uma forma negativa para o contexto legal, limitando-se a declarar os casos em que a imputabilidade é excluída, a qual, como já foi dito, traz como conseqüência imediata a culpabilidade e esta faz surgir a responsabilidade penal. Tal procedimento, além das razões de ordem técnico-legislativas de que fala Nelson Hungria, decorre, em última "ratio", da fertilidade e da riqueza axiológica do tema que não se molda aos limites de uma definição.

Por tal forma, frente à nossa lei, com base em um raciocínio a contrário senso, chega-se à conclusão que é imputável, conseqüentemente, capaz de suportar uma carga de culpa com a responsabilidade daí decorrente, todo o homem que reúne as condições mínimas e necessárias de capacidade para entender e discernir o justo do injusto e, ainda, o poder de auto determinar-se diante dos motivos que influenciam a vontade. Capacidade que se vincula à racionalidade e poder que emana da liberdade são, pois, os pressupostos fundamentais da responsabilidade penal. 1. Giulio Battaglini - Direfto Penal - tradução brasileira pág. 218 "A Imputabilidade ${ }^{2}$ um status que serve de condicáo para a culpabilidade. A imputabila
dade concerne à estrutura do delito: porém, não como seu elemento, mas, mais exatamente como pressuposto daquele elemento constituído pela culpabillidade"

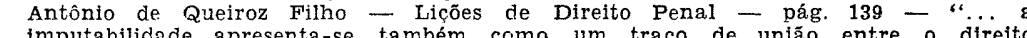
penal e a criminologia 